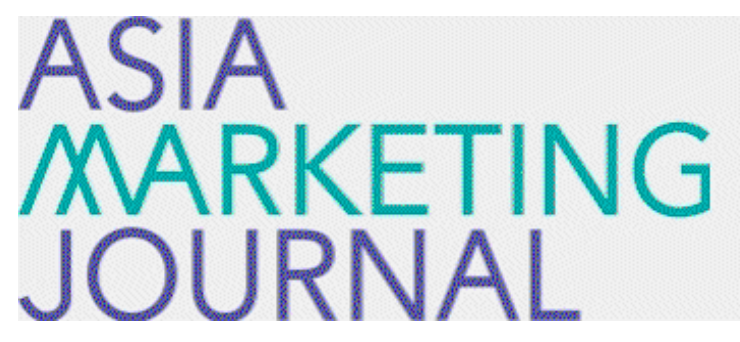

ASIA MARKETING JOURNAL

Volume 21 | Issue 1

Article 5

4-30-2019

\title{
Social Identity and Regulatory Focus
}

Sangwoo Park

Dakyeong Heo

Dongwoo Shin

Follow this and additional works at: https://amj.kma.re.kr/journal

Part of the Marketing Commons

\section{Recommended Citation}

Park, Sangwoo; Heo, Dakyeong; and Shin, Dongwoo (2019) "Social Identity and Regulatory Focus," Asia Marketing Journal: Vol. 21 : Iss. 1 , Article 5.

Available at: https://doi.org/10.15830/amj.2019.21.1.89

This Article is brought to you for free and open access by Asia Marketing Journal. It has been accepted for inclusion in Asia Marketing Journal by an authorized editor of Asia Marketing Journal. 


\title{
Social Identity and Regulatory Focus: Can Collective Orientation Influences Consumers' Message Evaluation?
}

\author{
Sangwoo Park* \\ Dakyeong $\mathrm{Heo}^{* *}$ \\ Dongwoo Shin ${ }^{* * *}$
}

\begin{abstract}
To investigate the interplay between individual and collective self-regulations, the authors propose a dialectic process that describes the changes in the locus of self-regulations between individual self and collective self. The results from three studies display a strong support for the two sets of hypotheses drawn from the proposed process. Our findings demonstrate that consumers can move the locus of self-regulation from individual-self to collective-self when a social identity is activated (preliminary study and study1). Further examination of regulatory swing between individual and collective regulatory orientations revealed group identification as a key variable in determining the locus of self-regulation (study2). While a consumer with a high level of group identification changes her locus of selfregulation from an individual to a collective (a regulatory shift) and evaluated messages and products framed consistent with their group orientation, a consumer with low level of group identification maintains her locus of self-regulation in her personal level of self (a regulatory preservation) and evaluated messages and products framed consistent with their personal regulatory focus.
\end{abstract}

Key words: Social Identity, Regulatory Focus, Message Evaluation, Self-Regulation

* Ph.D. Candidate, School of Business Administration, University of Seoul, Jeonnong-Dong 90, Dongdaemun-Gu, Korea (sangwoo.park8305@gmail.com), First Author

** Lecturer, School of Business Administration, University of Seoul, Jeonnong-Dong 90, Dongdaemun-Gu, Korea (shinydk@gmail.com)

*** Professor, School of Business Administration, University of Seoul, Jeonnong-Dong 90, Dongdaemun-Gu, Korea (dshin@uos.ac.kr), Corresponding Author 


\section{Introduction}

Christopher is usually shy and has a very reserved personality. He prefers staying indoors and watch movies to doing some exciting outdoor activities. He recently entered a University whose members share a very outgoing and enthusiastic culture. In this university's rich and extremely sociable culture he experienced a lot of exciting activities he usually would not enjoy before. While he was wandering around its campus with his friends, he ran into an advertisement describing an exciting summer leisure programs which includes paragliding and kitesurfing. Christopher thought "hmm $\cdots$ that can be fun..." and asked his friends if they are willing to join the program.

As we can see from this short example, a consumer, often without thinking about it, got influenced by a group identity and use its norms and values to guide his consumption behaviors toward a more desirable direction. Although consumer researchers have paid high interest on both a consumer's individual self-regulations (e.g., Craciun et al. 2017; Dewitte et al. 2009; do Vale et al. 2008; Hong and Lee 2008) and the influences of a collective on a consumer's self-regulations (e.g., Epp and Price 2008; Mandel 2003; Zhang and Shrum 2009), to the best of our knowledge, no study has examined the interplay between individual and collective self-regulations - when and how a consumer uses (or does not use) a group's norm and values related to a goal striving process to guide the individual's consumption behaviors.

To understand the interplay between two different levels of self-concepts on a consumer's self-regulations, we develop a dialect process of self-regulation by integrating two influential theories: Social Identity Theory (Tajfel 1982; Turner and Onorato 1999) and Regulatory Focus Theory (Higgins 1997). In this process, three novel concepts - the regulatory conflicts (i.e., the inconsistency between a group's regulatory orientation and a personal regulatory focus), the regulatory shift (i.e., changing the locus of self-regulation from an individual to a group), and the regulatory preservation (i.e., maintaining the locus of self-regulation in the individual self) plays a crucial role in explain when and how a consumer swing her locus of self-regulation between individual self and collective self.

Our model postulates that when a consumer experiences inconsistency between collective and individual self-regulations, she is compelled to reduce the psychological pressure from the regulatory conflict, and implement one of the two routes to do so. A consumer with a high level of group identity will go through a regulatory shift where she changes the locus of selfperception from an individual identity to a group identity, and follows the group's regulatory norms. On the other hand, a consumer with a low level of group identification will go through 
a regulatory preservation where she maintains her individual self-perception and follow her personal self-regulatory orientations.

We tested two sets of hypotheses drawn from our model with an empirical framework developed for examining the congruence between message framing and regulatory focus (Aaker and Lee 2001; Lee and Aaker 2004). One preliminary study and two main studies demonstrate the following results. First, consumers can shift their locus of self-regulation from individual to group with an activation of a social identity. Second, the regulatory shifts influence consumers' message and product evaluations. Third, while consumers with high level of group identification demonstrate regulatory shift from individual to collective, consumers with low level of group identification maintain their personal regulatory orientations.

\section{Regulatory Focus, Group Orientation, and Regulatory Shift}

The regulatory function of the self enables a person to control the individual's goal directed actions (Baumeister 1998). Regulatory focus theory (Higgins 1997; 2000) proposes that the characteristics of self-regulatory functions can be shaped by two distinct goals: ideals (e.g., hopes, wishes, aspirations) lead to promotion focus and oughts (e.g., safety, duties, responsibilities) generate prevention focus. Promotion focus is sensitive to the presence and absence of positive outcomes, and prefers eagerness strategies to maximize gains and minimize nongains. Prevention focus is sensitive to the presence and absence of negative outcomes and favors vigilance strategies to avoid losses and attain nonlosses. The theory provides an interesting perspective by specifying the contextual influences on people's regulatory foci. Although people favor one regulatory focus over the other, they maintain both regulatory systems in their minds, which can provide them abilities to implement flexible self-control strategies by activating a regulatory system more appropriate to the imminent social situation.

The extant research on regulatory focus heavily emphasizes on its role in individual level self-regulation processes (Dholakia et al. 2006; Hong and Lee 2008; Keller 2006; Pham and Avnet 2004; Wan et al. 2009; Yeo and Park 2006). Few studies examines collective influences on individuals' regulatory focus with variables such as self consturals (Aaker and Lee 2001), cultural values (Lalwani et al. 2009), or leadership styles (Kark and Van Dijk 2007). In this paper, however, we further argue that a group can develop a distinct regulatory focus as a collective norm, and can play a fundamental role in managing people's regulatory foci. To make a clear distinction between the two different levels of regulatory focus, we named the individual regulatory focus as (prevention 
vs. promotion) personal regulatory focus and the collective regulatory focus as (avoidance vs. approach) group orientation.

The notion of group orientation, defined here as a regulatory norm of a collective developed through social interactions among the members to achieve its common goal(s), is developed by integrating Social Identity Theory (Turner et al. 1987) and Regulatory Focus Theory (Higgins 1997; Higgins 2000). When people categorize themselves as a member of a group, they define themselves with a stereotypical representation of the group (i.e., perceive the self as 'we' rather than 'I'), and share the group's motivations, perspectives, and group norms. A few studies (e.g., Hogg and Reid 2006; Jetten et al. 2002; Postmes et al. 2001) demonstrate that this "shared" beliefs among group members is the foundations of intra- or intergroup behaviors. Higgins and his colleagues (e.g., Higgins 1996; Higgins and Spiegel 2004) also used the shared ideas among peers or family members as a foundation of an individual's regulatory focus: whereas an individual surrounded by family members and peers who "share" ideal goals would develop promotion focus, and individual surrounded by peers or family members who "share" ought goals would develop prevention focus.

We argue that, analogous to the process of developing individuals' personal regulatory foci, a collective can develop a group orientation as a form of shared group norm through collective goal settings and interactions among group members. Group members would develop approach group orientation comparable to promotion focus if the group's objective has promotion characteristics, and the members share eagerness strategies to achieve the group goal. On the other hand, group members would develop avoidance group orientation comparable to prevention focus if the group's objective has prevention characteristics, and the members share common understandings of implementing vigilance strategies to obtain the group goal.

With an activation of a group membership, people re-define themselves with prototypical images of the group membership, and use the group's motivation, perspectives, and norms to guide their behaviors (e.g., Ellemers et al. 2008; Norton et al. 2003; Turner et al. 2008). Following the same line of reasoning, when a consumer encounters a group situation, she defines herself with the group membership and temporarily shifts the locus of self-regulation from personal regulatory focus to the group orientation to guide her behaviors in accordance with the group's shared goal characteristics (i.e., approach/avoidance). For instance, when a consumer dines with a small group of friends who shares the same concern of losing weight, although she personally loves to enjoy hearty and tasty food (i.e., promotion orientation), she will more likely adopt the group's avoidance orientation (i.e., watching the diet and losing weight) and chooses low calories plates. In such 
a social context, the avoidance group orientation can momentarily replace an individual's promotion regulatory focus, which we named as regulatory shift in this paper.

To demonstrate the viability of the regulatory shift from personal regulatory focus to group orientation, we examine the congruence between group orientation and message framing. One of the important empirical frameworks for testing the impact of regulatory focus is the examination of congruence (or incongruence) between marketing stimuli and regulatory focus (e.g., Aaker and Lee 2001; Dholakia et al. 2006; Hong and Lee 2008; Mehdi et al. 2007; Pham and Avnet 2004; Wan et al. 2009; Yeo and Park 2006). A few of studies demonstrated that a consumer with a promotion focus evaluates a promotion-framed message more favorable, while a consumer with a prevention focus evaluates a prevention-framed message more favorable (Aaker and Lee 2001; Chernev 2004; Lee and Aaker 2004; Lee and Aaker 2000). By combining the congruence hypotheses with the regulatory shift, we predict that group members will prefer a messages framed consistently with their group orientation (i.e., approach group - promotion framing and avoidance group - prevention framing) regardless of their personal regulatory focus when a group membership is made salient. The expected pattern of regulatory shift and message congruence is formally stated in the following hypotheses:
Hypothesis 1-a: With an approach group orientation, consumers will evaluate a promotion framed message more favorably than a prevention framed one.

Hypothesis 1-b: With an avoidance group orientation, consumers will evaluate a prevention framed message more favorably than a promotion framed one.

\section{Preliminary Study: Do Regulatory Shifts Happen?}

A 2 (group orientation: avoidance vs. approach) $\times 2$ (personal regulatory focus: prevention vs. promotion focus) study is designed to examine the assumption that when people's group identity made salient, the group's goal orientation will temporarily replace the group members' personal regulatory tendencies (i.e., regulatory shifts). A total of 123 participants from a large public university completed the study for partial fulfillment of course credit.

At the beginning of the study, the participants completed a battery of questions that includes 11-item Regulatory Focus Questionnaire (RFQ, Higgins et al. 2001) measuring an individual's personal regulatory focus. The scores of promotion and prevention sub scales were averaged, and we used the difference between the averages of two subscales (i.e., promotion - prevention) to measure individuals' personal regulatory 
focus (Higgins et. al. 2001). Then promotion and prevention conditions were later created with a median split on the measure.

Upon completing the questionnaire, participants were randomly assigned into a group of three people and asked to play and evaluate a family game (Pop up Pirate). Each group was randomly assigned to one of the conditions (avoidance or approach) to activate a group orientation (Onorato and Turner 2004). In the approach condition, participants were primed to provide as many right choices as possible, which encourage them to focus on psychological gains and to implement eagerness strategies. In the avoidance condition, participants were primed to make as few mistakes as possible, which encourage them to concentrate on psychological losses and to use vigilance strategies. When all participants finished the game, they were asked to complete a questionnaire that includes three items that measuring participants' current status of regulatory orientation (Pham and Avnet 2004).

The results from the ANOVA analyses supported the assumption of regulatory shift by showing a significant main effect of group orientation $(p=.045)$. The personal regulatory focus and the interaction between group orientation and personal regulatory focus did not display significant test results ( $p$-values are 0.833 and 0.701 respectively). The approach group orientation condition showed a higher cell mean (4.35) than the avoidance condition
(3.94) generating a pattern consistent with our prediction of regulatory shift given a higher score represents more promotion oriented mindset.

\section{Study 1: Regulatory Shift and Message evaluation}

Since the preliminary study demonstrates the feasibility of group orientation, we further examine if the regulatory shift can influence the group members' evaluative processes, and generate the congruence effect proposed in hypotheses $1 \mathrm{a}$ and $1 \mathrm{~b}$. If the regulatory shift hypothesis holds, the message congruent with the group orientation will receive a more favorable evaluation than the one incongruent with the group orientation.

\subsection{Method}

A total of 149 participants were recruited from a large southern public university and received extra credit for their participation. They were randomly assigned into a 2 (group orientation: avoidance vs. approach) $\times 2$ (message framing: prevention vs. promotion) between subject factorial design. Upon entering the experiment lab, participants were told that they will participate in two ostensibly unrelated studies, one examining a family game product and the other evaluating a print advertisement. 
The former was designed to manipulate the participants' group orientations and the latter was constructed to examine the congruence effect between the group orientation and message framing.

\subsubsection{Group Orientation Manipulations}

Participants were randomly assigned into a group of three people, and the members of each group were seated around a round table. They were asked to solve a collective quiz game (Team Jeopardy!). Then, each group was randomly assigned to one of the two conditions (avoidance or approach) to prime group orientations (Onorato and Turner 2004). To create the approach group orientation, the participating groups were instructed to answer as many questions as possible without any penalty for providing wrong answers, which primes participants to focus on psychological/ financial gains and to prefer eagerness strategies. The following instructions were used to frame the game with the approach group orientation.

Imagine you and your team members as contestants playing Team Jeopardy!. You and your team members must work as a group and reach a consensus before answering each question. Your team will be asked to answer 20 questions and your team's task is solving as many questions as possible. You will have 10 minutes and your team will gain $\$ 100$ for each question you answered right. Furthermore, if your team scores
$\$ 1,000$ or more points than the last year's national average, all of your group members will gain the chance of moving to the next round, where teams will compete for the regional championship.

To create the avoidance group orientation, the participants were instructed to make as few mistakes as possible by penalizing them for providing wrong answers, which primes participants to reflect upon psychological/ financial losses and to prefer vigilance strategies. The following instruction was used to manipulate the avoidance group orientation.

Imagine you and your team members as contestants playing Team Jeopardy!. You and your team members must work as a group and reach a consensus before answering a question. Your team will be asked to answer 20 questions and your team's task is making as few mistakes as possible. You will have 10 minutes and your team will lose $\$ 100$ for each question you answered wrong. Furthermore, if your team scores $\$ 1,000$ or less points than the last year's national average, all of your group members will lose a chance of moving to the next round, where teams will compete for the regional championship.

\subsubsection{Message Framing Manipulations}

A variation of Lee and Aaker's (2004) procedure is applied to generate prevention/ promotion advertisement messages. Participants randomly received one of two print advertisements (prevention framed vs. promotion framed) 
about "9 to 5," a fictitious sunscreen brand. The advertisement message in prevention condition was framed as "Golf, tennis, or at the beach, worrying about sunburns and skin irritation is troublesome. Keep your skin safe with "9 to 5" and prevent harmful sunburn and pre-cancerous spots." The advertisement message in the promotion condition was constructed as follows: "Golf, tennis, or at the beach, "9 to 5" lets you stay in the sun longer and promotes good times. Live life to the fullest with "9 to 5" and enjoy your favorite outdoor activities." Both the messages were presented with a picture of the product. After examining the framed advertisements, participants were asked to complete a questionnaire containing items measuring the dependent variables and other unrelated questions. While answering these questionnaire items, participants were instructed not to communicate with their team members.

\subsubsection{Measures of Dependent Variables}

Three dependent variables: Message Persuasiveness (MP), Brand Attitude (BA), and Personal Relevance (PR) were used to examine the impact of regulatory shift in message evaluation. MP was measured with three semantic differential measures - persuasive/ not persuasive, informative/uninformative, and believable/unbelievable (Goodstein 1993; Yi 1993). BA was measured with the five seven- point semantic differential measures - good/ bad, favorable/unfavorable, positive/negative, desirable/undesirable, and beneficial/harmful (Wheeler et al. 2005). PR toward sunscreen product, which indicates the personal importance of the product category, was assessed with three 7-point Likert scale items (Priester et al. 2004) anchored with 'not at all important'/ 'extremely important,' 'not at all self-relevant'/ 'extremely self-relevant,' and 'have not thought about at all'/have thought about it a great deal.' Each of these three sets of scales was averaged to create the three composite variables of MP $(a=.78)$, BA $(a=.90)$, and PR $(a=.77)$.

\subsection{Results and Discussion}

A $2 \times 2$ MANOVA with the three dependent variables $(\mathrm{MP}, \mathrm{BA}$, and $\mathrm{PR})$ revealed a marginally significant interaction effect of Group Orientation and Message Framing $(F(3,142)=2.476$, $p=.064)$. Both main effects of Group Orientation and Message Framing were not significant. Then, three separate ANOVAs were conducted to exam if the interaction pattern on each dependent variable shows the hypothesized congruence effect.

ANOVA on MP showed the expected significant interaction effect between group orientation and message framing (see table $1 ; F(1,144)=$ $4.321, p<.05)$. In the avoidance group orientation condition, prevention framed messages (4.58) 
was evaluated more favorable than promotion framed message $(3.72, F(1,144)=8.072, \mathrm{p}<$ $.01)$. On the other hand, in the approach group orientation, there was no significant difference between the evaluations of the two messages ( promotion $=4.19$ and prevention $=4.19$, $F(1,144)=0.00$, ns). There was also a significant main effect for message framing $(F(1,144)=4.246, p<.05)$ indicating that prevention framed message $(\mathrm{M}=4.36, \mathrm{SD}=$ 1.19) were evaluated more favorably than promotion framed message $(\mathrm{M}=3.95, \mathrm{SD}=$ 1.33). The main effect for the Group Orientation condition was not significant $(F(1,144)=$ 0.031 , ns). The results from both ANOVAs on $\mathrm{BA}$ and $\mathrm{PR}$ revealed no significant effect of Group Orientation, Message Framing, or the interaction of the two experimental factors (see table 1).

In study 1 , we found that the congruence effect between message framing and collective orientation was limited on MP, and was not extended to the other dependent variables BA or PR. We suspect that such a partial support of regulatory shift hypothesis can be attributed to the variation in the levels of group identification among participants. The simple use of anonymous group in the experimental procedure may have generated contexts where some participants activate only a minimal level of cognitive categorization. Previous research (e.g., Bergami and Bagozzi 2000; Ellemers et al. 2002; Swann et al. 2009) suggested that different levels of group identification generate asymmetric group effects. It is possible that participants have different levels of group commitment even though they followed the same procedure of cognitive activation of group categorization. If so, people with low level of group identification are less influenced by group orientation, and therefore fail to generate fullfledged regulatory shifts.

The unexpected main effect may come from the stereotypical image of the sunscreen product. Previous research showed that products with a certain goal orientation (e.g., promotion for stock trading and prevention for mutual fund) may activate a different regulatory focus in consumers mind (Zhou and Pham 2004). This experiment is conducted in a southern state,

$\langle$ Table1〉 Cell Means of Study1

\begin{tabular}{cccccccccc}
\hline & \multicolumn{3}{c}{ Approach } & & \multicolumn{3}{c}{ Avoidance } \\
\cline { 2 - 3 } $\begin{array}{c}\text { Dependent } \\
\text { Variable }\end{array}$ & $\begin{array}{c}\text { Promotion } \\
(\mathrm{n}=38)\end{array}$ & $\begin{array}{c}\text { Prevention } \\
(\mathrm{n}=40)\end{array}$ & $\begin{array}{c}\text { Pro } \\
\text { vs. } \\
\text { Pre }\end{array}$ & & $\begin{array}{c}\text { Promotion } \\
(\mathrm{n}=39)\end{array}$ & $\begin{array}{c}\text { Prevention } \\
(\mathrm{n}=31)\end{array}$ & $\begin{array}{c}\text { Pro } \\
\text { vs. } \\
\text { Pre }\end{array}$ \\
\hline Message Persuasiveness & 4.19 & 4.19 & .00 & & 3.72 & 4.58 & $-.86^{* *}$ \\
Brand Attitude & 4.64 & 4.71 & -.07 & & 4.62 & 5.06 & -.44 \\
Personal Relevance & 4.68 & 4.51 & .17 & & 4.39 & 4.71 & -.32 \\
\hline
\end{tabular}


and a sunscreen product can be viewed as prevention related item especially in the state where strong sunlight worries people more than other areas of US. Such a typical image of the product might have made participants more susceptible to messages consistent with such typicality and make the prevention message more persuasive than the promotion message, and generated the significant main effect of Message Framing.

\section{Regulatory Shift vs. Regulatory Preservation}

While the regulatory shift hypothesis provides a meaningful explanation on how group orientation influences individual consumers' regulatory functions, it does not provide a sufficient justification on some important issues on group influence such as anti-normative behaviors or individuals' resistance against collective influences (e.g., Ennett and Bauman 1994: Venkatesan 1966). One can often observe group situations where people are cognitively aware of their group memberships, but refuse to go along with the group's norms, values, and goal orientations. For instance, in a different group context of eating out with co-workers for a celebration (i.e., approach group orientation) of achieving the annual goal, another consumer may stick to her personal prevention goal (not gaining weight), and restrain herself from eating and drinking while all other co-workers are celebrating and enjoying their achievements. A consumer's regulatory choice in a group context may not be solely dominated by unidirectional group influences but be determined by the interaction between personal and collective regulatory systems. To examine the interplay that shapes a consumer's current regulatory state, we introduce the concept of regulatory conflict - the inconsistency between a person's own personal regulatory focus and the group's goal orientation. As an attempt to explain why some individual consumers simply shift their regulatory focus to group orientation while some others resist doing so while they were experiencing regulatory conflicts, we developed a dialectic process of conflict resolution process. Prior research suggests the influence group norm on individual members differs depending on the levels of group identification (e.g., Bergami and Bagozzi 2000; Jetten et al. 2002; Swann et al. 2009). A high level of group identification often leads an individual to see the collective as part of the self and uses group norms to guide her behaviors while a low level of group identification make an individual to see the collective to be more detached from the self and resists group norms.

We propose two distinct conflict resolution processes (regulatory shift vs. regulatory preservation), in which a consumer choose one of the two processes depending on the level of 
group identification. A consumer with a high level of group identification may go through a complete depersonalization process, where she defines herself with her group membership (Ellemers et al. 2002), see the group as a part of her self-definition, and use the group orientation as the active regulatory focus. On the other hand, a consumer with low level of group identification would not follow depersonalization and maintain her own personal regulatory tendency as the active regulatory focus. By doing so, she can maintain a more flexible and appropriate regulatory system that helps her to achieve personal consumption goals and to maintain healthy social relationships. When these two different conflict resolution processes are connected with a message congruence hypothesis, the following formal hypotheses are generated;

Hypothesis 2-a: When experiencing regulatory conflicts, consumers with high group identification will evaluate a message congruent with their group orientation more favorably than one congruent with their personal regulatory focus.

Hypothesis 2-b: When experiencing regulatory conflicts, consumers with low group identification will evaluate a message congruent with their personal regulatory focus more favorably than one congruent with their group orientation.

\section{Study 2: Group Orientation or Personal Regulatory Focus?}

In study 2, we explore the interplay between group orientation and regulatory focus by examining the moderating role of group identification in regulatory shift, and its consequences on message and brand evaluations.

\subsection{Method}

Regulatory Conflicts were created by mismatching participants' group orientations with their personal regulatory foci (i.e., avoidance GO promotion RF and approach GO - prevention $\mathrm{RF}$ ). Hence, a 2 (Regulatory Conflict: avoidance GO - promotion RF vs. approach GO prevention $\mathrm{RF}) \times 2$ (Group Identification: high vs. low) $\times 2$ (Message Framing: promotion vs. prevention) between subjects design is implemented to test the suggested hypotheses. 294 students from a large southern public university participated in this study and received course credit. Upon arriving, participants were greeted by two experimenters and told that the experiment is composed of three sessions. The first two for creating regulatoryconflict and inducing different levels of group commitment, and the last for manipulating message framing and measuring the dependent variables. 


\subsubsection{Regulatory Conflict (RC) Manipulation}

In the first session, which is allegedly conducted by the university's career service center, participants were randomly assigned into two conditions, and then asked to write essays focused on either their hopes and aspirations (promotion) or duties and obligations (prevention) in order to prime their personal regulatory foci (Molden and Higgins 2004). In the second session, participants were instructed to play and examine a collective gaming product solving a series of graphical puzzles as a team with either approach or avoidance goal orientation (Plaks and Higgins 2000). To create the two $\mathrm{RC}$ conditions, participants previously exposed to the promotion RF manipulation were assigned to avoidance GO, and those previously exposed to the prevention $\mathrm{RF}$ manipulation were assigned to approach GO.

In approach $\mathrm{GO}$ condition, the collective game was framed to emphasize financial/ psychological gains and to induce eagerness strategies for the group members. The following instruction was given to participants in Prevention RF - Approach GO condition.

Imagine you and your team members as contestants playing Team Tangram! in the first round. On your table, there is a wooden square divided into seven pieces with different sizes and shapes, which can be put together again in hundreds of different figures and forms. Your team will be asked to reproduce the silhouettes shown in this booklet with these seven wooden pieces. You must work as a group and your task is to reproduce as many silhouettes as possible. Your team's goal is to gain a chance to move to the next round. Your team will gain $\$ 1,000$ for each puzzle you solve together with your group. Furthermore, if your team scores higher than the last year's national average, all of your team members will gain extra $\$ 1,000$ and a chance to move to the next round.

On the other hand, in Avoidance GO, the collective game was framed to emphasize financial/psychological losses and to induce vigilance strategies for the group members. The following instruction was given to the participants in promotion RF - avoidance GO condition.

Imagine you and your team members as contestants playing Team Tangram! in the first round. On your table, there is a wooden square divided into seven pieces with different sizes and shapes, which can be put together again in hundreds of different figures and forms. Your team will be asked to reproduce the silhouettes shown in this booklet with these seven wooden pieces. You must work as a group, and your team's goal is to avoid a situation where you fail to advance to the next round. Your team will lose \$1,000 for each puzzle you fail to solve. Furthermore, if your team scores lower than the last year's national average, all of your team members will lose an extra \$1,000 and lose a chance to move to the next round.

When participants finished the game, they 
were asked to complete a bogus questionnaire concerning different dimensions of the game.

\subsubsection{Group Identification (GI)}

To induce different levels of group identification, we applied a variation of the bogus pipeline procedure suggested by Ellemers, Spears, and Doosje (1997). At the beginning of the second session, participants were asked to complete a short questionnaire about what extent they agree with a number of general statements about their group membership. Then, while they were playing the game, participants were asked to wear a medical wristband which measures blood pressure, heart rate, and other physiological indices. Participants were led to believe that each wristband has a wireless connection with a computer program that calculates the strength of their group membership from their answers to the questionnaire and the physiological indices collected through the wristband while they were working on the group task.

Then, the level of GI was manipulated by providing participants a false feedback concerning their commitment toward the group activity. In the low GI condition, participants received a feedback-form indicating their group commitment score (25.2 points) was lower than the average (74.3 points). On the other hand, participants in the high GI condition were told that their score (82.6 points) is higher than the average
(14.3 points). The effectiveness of this manipulation was evaluated with a two item measure of social identity (Bergami and Bagozzi 2000). A t-test on the measure showed a significant difference between high GI $(\mathrm{M}=4.60)$ and low GI $(\mathrm{M}=3.70, p<.01)$.

Message Framing (MF). In the last session, participants were asked to evaluate one of the two advertisements (i.e., promotion framed vs. prevention framed) identical with the ones used in study 2. Then they were asked to complete a questionnaire that contains the same measures of Message Persuasiveness (MP, $a=.81$ ), Brand Attitude (BA, $a=$ .91 ), and Personal Relevance (PR, $a=.74$ ) used in study2.

\subsection{Results and Discussion}

To test the proposed hypotheses, we conducted a $2 \times 2 \times 2$ MANOVA with MP, BA, and PR. Neither gender nor age did show a significant effect, and dropped from further analyses. Multivariate tests on three dependent variables found the expected three-way interaction of $\mathrm{RC}, \mathrm{GI}$, and $\mathrm{MF}$ to be significant $(\mathrm{F}(3,283)$ $=5.068, p<.01)$. None of other main effects or three two-way interaction effects was found significant. To further exam the observed interaction, a series of three $2 \times 2 \times 2$ ANOVAs on each of MP, BA, and BR were conducted. The cell means and standard deviations from those models are displayed in Table 2. 
$\langle$ Table 2〉 Cell Means of Study 2

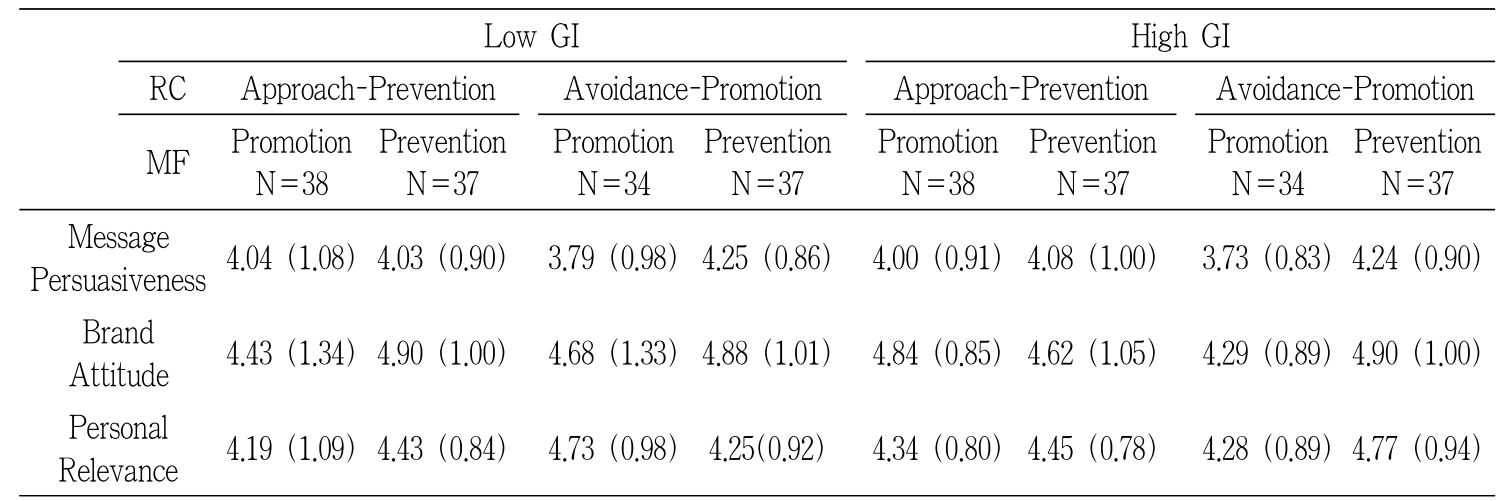

Note: All the variables in the above table range from 0 to 7 . Standard deviations are shown in parentheses.

$\mathrm{GI}=$ Group Identification, $\mathrm{RC}=$ Regulatory Conflict, and MF $=$ Message Framing

ANOVA on MP showed a significant main effect of message framing $(F(1,285)=5.626$, $p<.05)$ and a significant two-way interaction between $\mathrm{MF}$ and $\mathrm{RC}(\mathrm{F}(1,285)=4.278, p<$ $.05)$, but fail to show a significant result for the expected three-way interaction predicted by regulatory conflict hypotheses. The two-way interaction showed a consistent pattern (i.e., regulatory shift) observed in study 1 . Participants exposed to avoidance-promotion $\mathrm{RC}$ condition perceived prevention framed message more persuasive than promotion framed message $($ Mpro $=3.76$ vs. Mpre $=4.24 ; \mathrm{F}(1,285)=$ 9.22, $p<.01)$ while participants exposed to approach-prevention $\mathrm{RC}$ condition perceived both promotion and prevention framed messages equally persuasive $($ Mpro $=4.02$ vs. Mpre = 4.05; $\mathrm{F}(1,285)=0.05$, ns $)$.

ANOVA on BA revealed a significant main effect of message framing $(F(1,285)=4.715$, $p<.05)$. Participants perceived prevention framed message $(M=4.14)$ more favorably than promotion framed message $(\mathrm{M}=3.90)$. Further, we found a significant three-way interactions $(\mathrm{F}(1,285)=5.052, \mathrm{p}<.05)$ expected from the hypotheses 2. In low GI and Approach-Prevention RC, participants evaluated the prevention framed brand more favorably $($ Mpro $=4.43$ vs. Mpre $=4.91 ; \mathrm{F}(1,285)=$ 4.14, $p<.05)$. In low GI and AvoidancePromotion RC, participants assessed both prevention and promotion framed brands similarly favorable $(\mathrm{Mpro}=4.68$ vs. Mpre $=4.89 ; \mathrm{F}(1$, $285)=0.63$, ns). On the other hand, participants evaluated both promotion and prevention framed brands equally favorable (Mpro $=4.84$ vs. Mpre $=4.62 ; F(1,285)=0.82$, ns $)$ in high GI and Approach-Prevention RC while participants evaluated prevention framed brand more favorably $($ Mpro $=4.29$ vs. Mpre $=4.90 ; \mathrm{F}(1$, 285) $=5.76, p<.05)$ in high GI and AvoidancePromotion RC. 
ANOVA on PR also displayed an expected significant three-way interaction $(\mathrm{F}(1,285)=$ $6.963, p<.01)$. None of other experimental factors was found to be significant. Participants in low GI and Approach-Prevention RC condition perceived both prevention and promotion framed brands similarly self-relevant (Mpro $=4.19$ vs. Mpre $=4.43 ; \mathrm{F}(1,285)=1.472$, ns $)$ while participants in low GI and Avoidance-Promotion $\mathrm{RC}$ condition perceived promotion framed brand more self relevant $(\mathrm{Mpro}=4.73$ vs. Mpre $=$ 4.25; $\mathrm{F}(1,285)=4.92, p<.05)$. On the other hand, participants in high GI and ApproachPrevention $\mathrm{RC}$ condition perceived both promotion and prevention framed brands similarly selfrelevant $(\mathrm{Mpro}=4.34$ vs. Mpre $=4.45 ; \mathrm{F}(1$, $285)=0.258$, ns) while participants in high GI and Avoidance-Promotion RC condition perceived prevention framed brand more self relevant $(\mathrm{Mpro}=4.28$ vs. Mpre $=4.77 ; \mathrm{F}(1,285)=$ 5.106, $p<.05)$.
Figure 1 displays these two three-way interaction patterns found on $\mathrm{BA}$ and $\mathrm{PR}$. These patterns suggest that participants use either personal regulatory focus or group orientations as their active regulatory foci depending on the level of group identification. For BA variable, we observed a clear crossover interaction expected from the proposed hypotheses in high GI condition while the pattern is not clear in low GI condition. On the other hand, for PR variable, we observed the expected crossover pattern in low GI condition and the interaction pattern in high GI condition is also consistent with the proposed hypotheses. From these interaction patterns, we are able to obtain a robust evidence supporting our predictions. The results demonstrated that consumers do change their regulatory orientation from individual level to the collective level (or vice versa) depending on the level of group commitment. When consumers possess low level of group

〈Figure 1> Moderating effct of $\mathrm{Gl}$ on BA and PR (study 2)

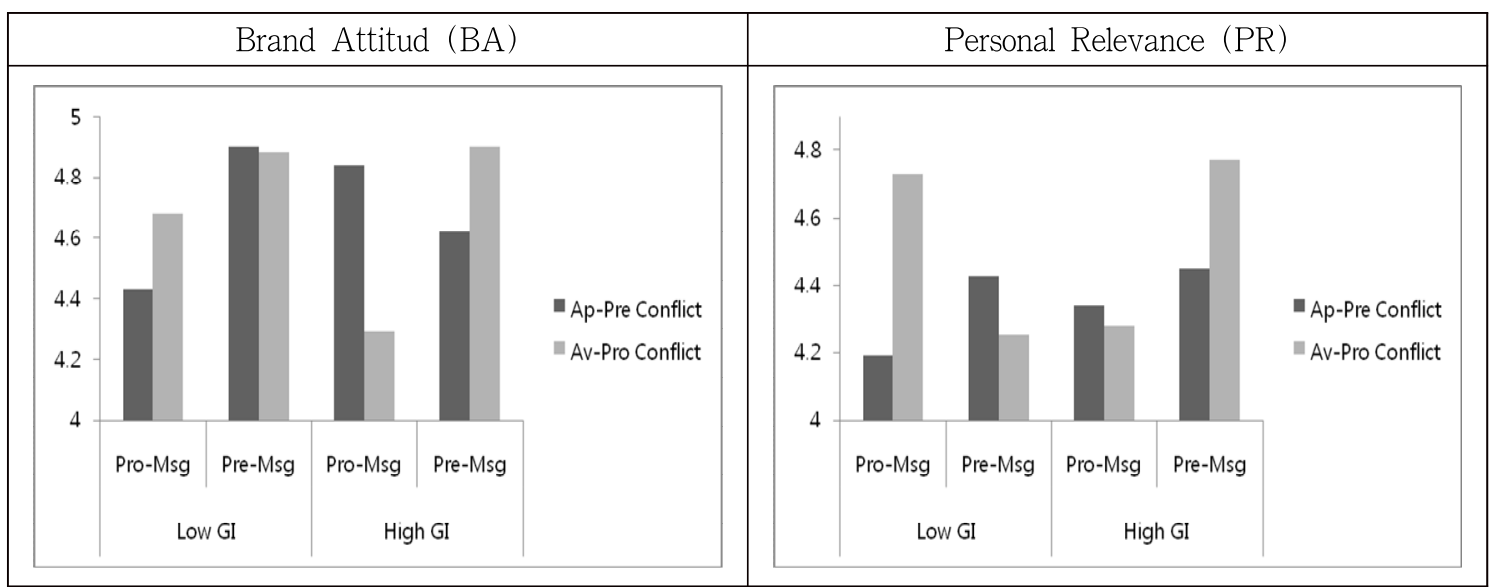


identification, they tend to follow personal regulatory orientation instead of group orientation. When consumers possess high level of group identification, consumers shift their locus of self-perception and use group orientation to regulate their evaluation processes.

\section{General Discussions}

The present research provides empirical supports the dialectic process of the regulatory shifts between individual and collective level of self-perceptions. The results from one preliminary study and two main studies demonstrate that 1) consumers can shift their locus of self-regulation from the individual level to the collective level when a social identity is made salient, 2) the shift in the regulatory focus influences consumers' message and product evaluations, 3) whereas consumers shift their regulatory focus to group orientation when they possess a high level of group identification, they maintain their personal regulatory focus when they did not have a strong identification with the group membership.

Specifically, with a simple activation of a group membership, we were able to show a partial support for the regulatory shift hypothesis. When a group has an approach (or avoidance) goal orientation, their group members' regulatory mindset becomes more promotion (or prevention) oriented (preliminary study). Interestingly, the changes in the locus of self-regulation generate a limited influence on message and product evaluations (study1). Under the speculation that this partial support of regulatory shift is due to the different levels of group identification between participants, we further examined the regulatory shift hypothesis with more elaborated hypotheses that propose a three-way interaction between regulatory conflict, group identification, and message framing. In study 2, we implemented the idea of regulatory conflicts to test the proposed hypotheses, and examined how the level of group identification determines a consumer's locus of self-control and influence her message and product evaluations (study 2). We found that when the level of group identification is low, participants evaluate a product framed consistent with their own personal regulatory tendency more favorable and selfrelevant. On the other hand, when the level of group identification is high, participants evaluate a product framed consistent with the group orientation more positive and self-relevant.

Although a couple of unexpected patterns emerged from individual ANOVA analyses, one should recognize that the results from MANOVAs showed a clear three-way interaction, as suggested from our hypotheses, and all other experimental factors became nonsignificant. We speculate that the superior statistical power of MANOVA (e.g., Iacobucci 1994) enables us to capture the true essence of 
the moderating effect of group identification. This strong three-way interaction in the MANOVA analyses, combined with the results from the three independent ANOVA analyses, provides meaningful evidence for the proposed CRP model.

To the best of our knowledge, our experiments represent the first attempt to demonstrate the dialectic interplay between collective and individual levels of self-regulations. Recent attempts of understanding collective influences on consumption behaviors has generated prolific researches on topics such as donations (Winterich et al. 2009), message effectiveness (Goldstein et al. 2008; Torelli 2006), purchase decisions (Lee and Shavitt 2006) and brand relationships (Swaminathan et al. 2007). Majority of such studies, however, have focused on the unidirectional influences of collectives on individual consumers and neglect the interplay between the individual identity and collectives. The current research contributes to the literature by providing a new approach to understand collective influences, which conceptualizes collective influences as a dynamic process that describes the interaction between two different levels of self-construals. Further, we implemented three novel concepts (regulatory conflicts, regulatory shift, and regulatory preservation) to genereate the proposed hypotheses, which present consumer researchers a useful framework for testing the interplay among different levels of self-construals (i.e., individual, relational, and collective: Sedikides and Brewer
2001) and its effect on consumers' consumption behaviors in various domains.

Our studies also provide additional evidence supporting the existence of collective regulatory orientation, and complement findings of prior research on regulatory focus. Whereas extant research primarily examined a collective regulatory goal as a contextual cue that activates the corresponding personal regulatory focus (Levine et al. 2000; Shah et al. 2004), the present research reformulates the concept as group orientation - a shared regulatory norm among group members that resides in an individual's collective self-concept. In addition, the current research advances the knowledge on how consumers manage to activate an appropriate regulatory focus in a given social context by examining the regulatory conflicts between a collective and the individual self. In the presence of a regulatory conflict, consumers are compelled to reduce the psychological tension between a collective and an individual identity. In such a situation, group identification plays an important role in helping consumers to resolve the conflicts and find a more appropriate self-regulation strategy.

The present study also provides an interesting insight regarding the impact of "a mere cognitive awareness of a group membership." A few empirical studies based on Social Identity Theory demonstrate that a simple awareness of group membership influences the members' perceptions and behaviors (e.g., Paladino and 
Castelli 2008). Although the preliminary study did show supporting evidence consistent with their findings, its effect was limited to consumer's perception on message congruence, which was not extended to product related variables. Consistent with the prior research (e.g., Bergami and Bagozzi 2000; Sleebos et al. 2006) that examined the moderating effect of group identification, our findings suggest that having a mere awareness of a group membership influence people, but the effect be limited to psychological domains close to the group identity. Further examination of regulatory shifts revealed that a higher level of group identification is necessary to generated fullpledged regulatory shifts among consumers, which also support the idea that the level of collective influences was determined by the level of group identification. Further, online marketers often use a consumer's group information (e.g., schools and universities they attended or companies and organizations they worked for) from SNS to influence her behaviors. However, they often develop communication messages based on the assumption that a simple awareness of group membership may influence a consumer's responses. Our research suggest that marketers should collect more detailed group-related information to enhance the effectiveness of their communication efforts.

The findings from the present research also have meaningful applications that can help consumers to promote desirable behaviors and prevent undesirable habits. Many consumers use support groups to maintain their wellbeings - from controlling excessive alcohol consumption to maintaining regular exercises. However, although consumers recognize the power of support groups, many of them often experiences failures in achieving such goals with groups' helps (Moisio and Beruchashvili 2010). It is more likely that a consumer with promotion focus may need a support group to implement avoidance group orientation (e.g., controlling overeating) because her natural tendency of self-regulation does not agree with the avoidance goal. If she can develop a strong attachment toward the support group (i.e., a high level of group identification), she have a higher chance of achieving the avoidance goal with a regulatory shift. Paradoxically, however, the collectively shared idea among consumers in individualistic and independent culture (Markus and Kitayama 1994) may prevent them from developing a strong identification with the support group. Rather, consumers often see the group as an entity separated from their self-perceptions and treat it as a means to achieve her individual (and independent) goal. Unfortunately, the psychological separation from a support group may hinder the regulatory shift and prevent consumer from taking a more effect way to achieve the desirable goal. Therefore, it is necessary to enlighten consumers to develop strong affective attachment toward support groups to increase the chance of 
achieving their goals though group efforts.

Our research has several limitations related to the methodological and theoretical issues of this paper. The implementation of the regulatory conflicts not only provides an interesting theoretical perspective but also generates a high level of efficiency in our experiments. Thus, theoretically uninteresting matches between personal regulatory focus and group orientation (i.e., promotion - approach and preventionavoidance) were not considered in our empirical studies. Although this empirical framework was effective in testing our proposed hypotheses, it prevents us from making clear explanations for some of unexpected effects related to $\mathrm{RC}$ (e.g., a main effect of RC on MP in study 2). Future studies focused on examining the precise mechanism of regulatory conflict manipulation would shed a new light on understanding how exactly consumers manage their conflict resolution process. In addition, the current research examined only the role of group identification in consumers' conflict resolution processes, where other social variables such as group leadership or group status (minority or majority) may also play important roles in shaping a consumer's regulatory functions. Further, since our experiments were conducted in small group contexts, one should be cautious about applying our findings in larger group settings where more complicated group dynamics are in play. Future researchers, however, also have wonderful opportunities of examining the conflict resolution process in large organization settings, where marketing department or sales teams often struggle to encourage their members to follow the group goals and induce desirable behaviors. One of possible sources of such a trouble can be a regulatory conflict between the departmental goals and individual employees, which deserve serious attention from group psychologists. For instance, sales department often clearly state their annual or monthly goals in a promotion framed way, and employees with prevention focus may experience "regulatory conflicts" that can impair their job satisfaction.

〈Received February 27. 2019〉 $\langle$ Accepted April 25. 2019〉

\section{References}

Aaker, Jennifer L. and Angela Y. Lee (2001), “' I' Seek Pleasures and 'We' Avoid Pains: The Role of Self-Regulatory Goals in Information Processing and Persuasion," Journal of Consumer Research, 28 (June), 33-49.

Baumeister, R. F. (1998), "The Self," in The Handbook of Social Psychology, Daniel T. Gilbert and Susan T. Fiske and Gardner Lindzey, eds. 4 ed. New York: Oxford University Preess.

Bergami, Massimo and Richard P. Bagozzi (2000), "Self-Categorization, Affective 
Commitment and Vroup Self-Esteem as Distinct Aspects of Social Identity in the Organization," British Journal of Social Psychology, 39(4), 555-577.

Chernev, Alexander (2004), "Goal Orientation and Consumers Preference for the Status Quo," Journal of Consumer Research, 31 (December), 557-565.

Craciun, Georgiana, Dongwoo Shin, and Jason Q Zhang (2017), "Safe Driving Communication: A regulatory Focus Perspective," Journal of Consumer Behaviour, 16(6), e50-e60.

Dewitte, S., S. Bruyneel, and K. Geyskens (2009), "Self-Regulating Enhances SelfRegulation in Subsequent Consumer Decisions Involving Similar Response Conflicts," Journal of Consumer Research, 36(3), 394-405.

Dholakia, Utpal M., Mahesh Gopinath, Richard P. Bagozzi, and Rajan Nataraajan (2006), "The Role of Regulatory Focus in the Experience and Self-Control of Desire for Temptations," Journal of Consumer Psychology, 16(2), 163-175.

do Vale, R. C., R. Pieters, and M. Zeelenberg (2008), "Flying under The Radar: Perverse Package Size Effects on Consumption Self-Regulation," Journal of Consumer Research, 35(3), 380-390.

Ellemers, N., S. Pagliaro, M. Barreto, and C. W. Leach (2008), "Is It Better to Be Moral Than Smart? The Effects of Morality and Competence Norms on the Decision to Work at Group Status Improvement,"
Journal of Personality and Social Psychology, 95(6), 1397-1410.

Ellemers, Naomi, Russell Spears, and Bertjan Doosje (2002), "Self and social identity," Annual Review of Psychology, 53(1), 161186.

(1997), "Sticking together of Falling Apart: In-group identification as A Psychological Determinant of Group Commitment versus Individual Mobility," Journal of Personality \& Social Psychology, 72(3), 617-626.

Ennett, Susan T. and Karl E. Bauman (1994), "The Contribution of Influence and Selection to Adolescent Peer Group Homogeneity: The Case of Adolescent Cigarette Smoking," Journal of Personality and Social Psychology, 67(4), 653-663.

Epp, A. M. and L. L. Price (2008), "Family Identity: A Framework of Identity Interplay in Consumption Practices," Journal of Consumer Research, 35(1), 50-70.

Goldstein, N. J., R. B. Cialdini, and V. Griskevicius (2008), “A Room with A Viewpoint: Using Social Norms to Motivate Environmental Conservation in Hotels," Journal of Consumer Research, 35(3), 472-482.

Goodstein, Ronald C. (1993), "Category-Based Applications and Extensions in Advertising: Motivating More Extensive Ad Processing," Journal of Consumer Research, 20 (June), 87-99.

Higgins, E. Tory (1996), "Shared Reality in 
The Self-System: The Social Nature of Self-Regulation," European Review of Social Psychology, 7, 1-29. (1997), "Beyond Pleasure and Pain," American Psychologist, 52 (12), 1280-300. (2000), "Making A Good Decision: Value from Fit," American Psychologist, 55(11), 1217-1230.

Higgins, E. Tory and Scott Spiegel (2004), "Promotion and Prevention Strategies for Self-Regulation: A Motivated Cognition Perspective," in Handbook of Self-Regulation: Research, Theory, and Applications., Roy F. Baumeister and Kathleen D. Vohs, eds.: Guilford Press.

Hogg, Michael A. and Scott A. Reid (2006), "Social Identity, Self-Categorization, and the Communication of Group Norms," Communication Theory, 16, 7-30.

Hong, Jiewen and Angela Y. Lee (2008), "Be Fit and Be Strong: Mastering Self-Regulation through Regulatory Fit," Journal of Consumer Research, 34 (February), 682-695.

Iacobucci, Dawn (1994), "Analysis of Experimental Data," in Principles of Marketing Research, Richard P. Bagozzi, ed. Cambridge, MA: Blackwell.

Jetten, Jolanda, Tom Postmes, and Brendan J. McAuliffe (2002), “'We're all individuals': Group Norms of Individualism and Collectivism, Levels of Identification and Identity Threat," Europenan Journal of
Social Psychology, 32 (April), 189-207. Kark, R. and D. Van Dijk (2007), "Motivation to lead, motivation to follow: The role of the self-regulatory focus in leadership processes," Academy of Management Review, 32(2), 500-528.

Keller, Punam A. (2006), "Regulatory Focus and Efficacy of Health Messages," Journal of Consumer Research, 33 (June), 109114.

Lalwani, A. K., L. J. Shrum, and C. Y. Chiu (2009), "Motivated Response Styles: The Role of Cultural Values, Regulatory Focus, and Self-Consciousness in Socially Desirable Responding," Journal of Personality and Social Psychology, 96(4), 870-882.

Lee, Angela Y. and Jennifer L. Aaker (2004), "Bringing the Frame into Focus: The Influence of Regulatory Fit on Processing Fluency and Persuasion," Journal of Personality \& Social Psychology, 86(2), 205-218.

(2000), "The Pleasures and Pains of Distinct Self-Construals: The Role of Interdependence in Regulatory Focus," Journal of Personality \& Social Psychology, 78(6), 1122-1134.

Lee, K. and S. Shavitt (2006), "The Use of Cues Depends on Goals: Store Reputation Affects Product Judgments When Social Identity Goals Are Salient," Journal of Consumer Psychology, 16(3), 260-271.

Levine, J. M., E. T. Higgins, and H. S. Choi 
(2000), "Development of Strategic Norms in Groups," Organizational Behavior and Human Decision Processes, 82(1), 88-101. Mandel, N. (2003), "Shifting Selves and Decision Making: The Effects of Self-Construal Priming on Consumer Risk-Taking," Journal of Consumer Research, 30(1), 30-40.

Markus, Hazel Rose and Shinobu Kitayama (1994), "A Collective Fear of the Collective - Implications for Selves and Theories of Selves," Personality and Social Psychology Bulletin, 20(5), 568-579.

Mehdi, Mourali, Ulf Bockenholt, and Laroche Michel (2007), "Compromise and Attraction Effects under Prevention and Promotion Motivations," Journal of Consumer Research, 34 (August), 234-247.

Moisio, R. and M. Beruchashvili (2010), "Questing for Well-Being at Weight Watchers: The Role of the Spiritual-Therapeutic Model in a Support Group," Journal of Consumer Research, 36(5), 857-875.

Molden, Daniel C. and E. Tory Higgins (2004), "Categorization Under Uncertainty: Resolving Vagueness and Ambiguity With Eager Versus Vigilant Strategies," Social Cognition, 22(2), 248-277.

Norton, M. I., B. Monin, J. Cooper, and M. A. Hogg (2003), "Vicarious dissonance: Attitude change from the inconsistency of others," Journal of Personality and Social Psychology, 85 (1), 47-62.

Onorato, Rina S. and John C. Turner (2004),
"Fluidity in the Self-Concept: The Shift from Personal to Social Identity," European Journal of Social Psychology, 34(3), 257278.

Paladino, M. P. and L. Castelli (2008), "On the Immediate Consequences of Intergroup Categorization: Activation of Approach and Avoidance Motor Behavior toward Ingroup and Outgroup Members," Personality and Social Psychology Bulletin, 34(6), 755-768.

Pham, Michel Tuan and Tamar Avnet (2004), "Ideals and Oughts and the Reliance on Affect versus Substance in Persuasion," Journal of Consumer Research, 30 (March), 503-518.

Plaks, Jason E. and E. Tory Higgins (2000), "Pragmatic Use of Stereotyping in Teamwork: Social Loafing and Compensation as a Function of Inferred Partner-Situation Fit," Journal of Personality \& Social Psychology, 79(6), 962-974.

Postmes, Tom, Russell Spears, and Sezgin Cihangir (2001), "Quality of Decision Making and Group Norms," Journal of Personality and Social Psychology, 80(6), 918-930.

Priester, Joseph R., Dhananjay Nayakankuppam, Monique A. Fleming, and John Godek (2004), “The A2SC2 Model: The influences of attitudes and attitude strength on consideration and choice," Journal of Consumer Research, 30 (March), 574-587. Sedikides, Constantine and Marilynn B. Brewer 
(2001), Individual Self, Relational Self, Collective Self. Philadelphia: Psychology Press.

Shah, James Y., Paige C. Brazy, and E. Tory Higgins (2004), "Promoting Us or Preventing Them: Regulatory Focus and Minifestations of Intergroup Bias," Personality and Social Psychology Bulletin, 30(4), 433-446.

Sleebos, E., N. Ellemers, and D. de Gilder (2006), "The Carrot and the Stick: Affective Commitment and Acceptance Anxiety as Motives for Discretionary Group Efforts by Respected and Disrespected Group Members," Personality and Social Psychology Bulletin, 32(2), 244-255.

Swaminathan, V., K. L. Page, and Z. GurhanCanli (2007), " "My” Brand or "Our” Brand: The Effects of Brand Relationship Dimensions and Self-Construal on Brand Evaluations," Journal of Consumer Research, 34(2), 248-259.

Swann, W. B., A. Gomez, D. C. Seyle, J. F. Morales, and C. Huici (2009), "Identity Fusion: The Interplay of Personal and Social Identities in Extreme Group Behavior," Journal of Personality and Social Psychology, 96(5), 995-1011.

Tajfel, H. (1982), Social Identity and Ingroup Relations. Cambridge, England: Cambridge University Press.

Torelli, C. J. (2006), "Individuality or Conformity? The Effect of Independent and Interdependent Self-Concepts on Public Judgments," Journal of Consumer Psychology, 16(3), 240-248. Turner, John C., Michael A. Hogg, Penelope J. Oakes, Stephen D. Reicher, and Margaret S. Wetherell (1987), Rediscovering the Social Group: A Self-Categorization Theory. Cambridge, MA: Basil Blackwell.

Turner, John C. and Rina S. Onorato (1999), "Social Identity, Personality, and the SelfConcept: A Self-Categorization Perspective," in The Psychology of The Social Self, Tom R. Tyler and Roderick M. Kramer and Oliver P. John, eds. Mahwah, NJ: Lawrence Erlbaum.

Turner, R. N., M. Hewstone, A. Voci, and C. Vonofakou (2008), “A Test of the Extended Intergroup Contact Hypothesis: The Mediating Role of Intergroup Anxiety, Perceived Ingroup and Outgroup Norms, and Inclusion of the Outgroup in the Self," Journal of Personality and Social Psychology, 95(4), 843-860.

Venkatesan, M. (1966), "Experimental Study of Consumer Behavior Conformity and Independence," Journal of Marketing Research, 3(4), 384-387.

Wan, Echo Wen, Jiewen Hong, and Brian Sternthal (2009), "The Effect of Regulatory Orientation and Decision Strategy on Brand Judgments," Journal of Consumer Research, 35 (April), 1026-1038.

Wheeler, S. Christian, Richard E. Petty, and George Y. Bizer (2005), “Self-Schema Matching and Attitude Change: Situational 
and Dispositional Determinants of Message Elaboration," Journal of Consumer Research, 31 (March), 787-797.

Winterich, K. P., V. Mittal, and W. T. Ross (2009), "Donation Behavior toward InGroups and Out-Groups: The Role of Gender and Moral Identity," Journal of Consumer Research, 36(2), 199-214.

Yeo, Junsang and Jongwon Park (2006), "Effects of Parent-Extension Similarity and Self Regulatory Focus on Evaluations of Brand Extensions," Journal of Consumer Psychology, 16(3), 272-282.
Yi, Youjae (1993), “Contextual Priming Effects in Print Advertisements: The Moderating Role of Prior Knowledge," Journal of Advertising, 22 (1), 1-10.

Zhang, Y. L. and L. J. Shrum (2009), "The Influence of Self-Construal on Impulsive Consumption," Journal of Consumer Research, 35(5), 838-850.

Zhou, Rongrong and Michel Tuan Pham (2004), "Promotion and Prevention Across Mental Accounts: When Financial Products Dictate Consumers' Investment Goal," Journal of Consumer Research, 31 (June), 125-135. 